\title{
Strontium enhances osseointegration of calcium phosphate cement: a histomorphometric pilot study in ovariectomized rats
}

Martin Baier ${ }^{1}$, Patric Staudt ${ }^{2}$, Roman Klein ${ }^{2}$, Ulrike Sommer², Robert Wenz ${ }^{3}$, Ingo Grafe ${ }^{2}$, Peter Jürgen Meeder ${ }^{1}$, Peter P Nawroth ${ }^{2}$ and Christian Kasperk ${ }^{2^{*}}$

\begin{abstract}
Background: Calcium phosphate cements are used frequently in orthopedic and dental surgeries. Strontium-containing drugs serve as systemic osteoblast-activating medication in various clinical settings promoting mechanical stability of the osteoporotic bone.

Methods: Strontium-containing calcium phosphate cement (SPC) and calcium phosphate cement (CPC) were compared regarding their local and systemic effects on bone tissue in a standard animal model for osteoporotic bone. A bone defect was created in the distal femoral metaphysis of 60 ovariectomized Sprague-Dawley rats. CPC and SPC were used to fill the defects in 30 rats in each group. Local effects were assessed by histomorphometry at the implant site. Systemic effects were assessed by bone mineral density (BMD) measurements at the contralateral femur and the spine.

Results: Faster osseointegration and more new bone formation were found for SPC as compared to CPC implant sites. SPC implants exhibited more cracks than CPC implants, allowing more bone formation within the implant. Contralateral femur BMD and spine BMD did not differ significantly between the groups.

Conclusions: The addition of strontium to calcium phosphate stimulates bone formation in and around the implant. Systemic release of strontium from the SPC implants did not lead to sufficiently high serum strontium levels to induce significant systemic effects on bone mass in this rat model.
\end{abstract}

Keywords: Strontium, Calcium phosphate cement, Osteogenesis, Bone healing, Osteoporosis

\section{Background}

Implant materials on the basis of calcium phosphate are frequently used with the goal of complete osseointegration and eventual substitution by the bone tissue [1-3]. Factors modulating bone formation are added to some implant materials to enhance osseointegration. The release of these factors occurs either spontaneously or as a consequence of the bony replacement of the implant. There have been numerous reports on osseous integration of organic and inorganic implant materials releasing growth factors like bone morphogenetic protein 2 (BMP-2) [4-7],

\footnotetext{
* Correspondence: christian.kasperk@med.uni-heidelberg.de ${ }^{2}$ Division of Osteology, Department of Medicine I and Clinical Chemistry, University of Heidelberg, Im Neuenheimer Feld 410, 69120, Heidelberg, Germany

Full list of author information is available at the end of the article
}

bone morphogenetic protein 7 (BMP-7) [8], fibroblast growth factor 2 (FGF-2) [9], platelet-derived growth factor [10], and insulin-like growth factors [11]. Some of these products are available for routine procedures. Although most of the published preclinical reports demonstrate a faster healing of osseous defects within the first 2 to 3 weeks, the clinical long-term relevance of these observations in animal experiments remains unclear.

Strontium administered systemically increases bone mass by stimulating osteoblastic activity [12-14] and simultaneously inhibiting bone resorption [15-17]. In preclinical experiments, oral administration of strontium ranelate prevented ovariectomy-induced bone loss in rats [15]. Subsequent clinical trials demonstrated a significant fracture prevention after strontium ranelate

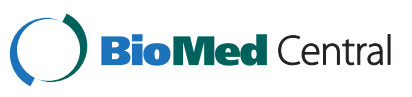


treatment of osteoporotic patients (TROPOS [18] and SOTI [19] studies).

We hypothesized that adding of strontium to calcium phosphate cement implants may improve osseous integration of the implant into the osseous implant bed and may also increase bone formation locally at the implanted skeletal site and systemically at the contralateral skeletal site and at the spine.

Osseointegration-stimulating properties of a bone substitute are of particular interest in an osteoporotic skeleton, which does not provide an optimal bone structure for surgical implantation procedures. To address this problem, we chose the ovariectomized rat model $[20,21]$ which is the standard animal model for the histomorphometric evaluation of bone healing in the osteoporotic bone.

The goals of our study were to assess osseointegration, compare calcium phosphate cement implants containing strontium (SPC) to calcium phosphate cement implants (CPC), and to determine whether a locally applied strontium-containing implant has systemic effects on bone mass.

\section{Materials and methods}

\section{Animal experiments}

The animal experiment was conducted in accordance with the guidelines set forth by the local animal protection committee of the regional government (Regierungspräsidium Karlsruhe, file number AZ 35-9185.82/A-49/04).

A standard animal model [20] for osteoporosis was used: 60 female Sprague-Dawley rats were ovariectomized at the age of 10 weeks under anesthesia with intraperitoneal injection of $100 \mathrm{mg} / \mathrm{kg}$ ketamine and $3 \mathrm{mg} / \mathrm{kg}$ xylazine and subcutaneous injection of carprofen (all three chemicals supplied by Pfizer, 76139 Karlsruhe, Germany).

Two months after ovariectomy, osteopenia was assessed by dual energy X-ray absorptiometry (Piximus device by GE, Fairfield, CT, USA). Successful ovariectomy-induced loss of bone mass was verified by measuring bone mineral density at the left femur (distal metaphysis) which exhibited a decrease of bone mineral density by $12 \%$ after 3 months as evaluated by the comparison to intact controls (data not shown).

Surgical procedure. In anesthesia, the right distal femur was exposed through a lateral approach. With a $2-\mathrm{mm}$ drill, a bone defect was created proximal to the distal femoral growth line in the lateral femoral cortex and the metaphyseal cancellous bone. The left femur was not operated on and served as control.

In 30 animals, the defect was filled with $0.25 \mathrm{ml}$ of $\mathrm{CPC}$ and in another 30 animals with the same volume of SPC (Figure 1).

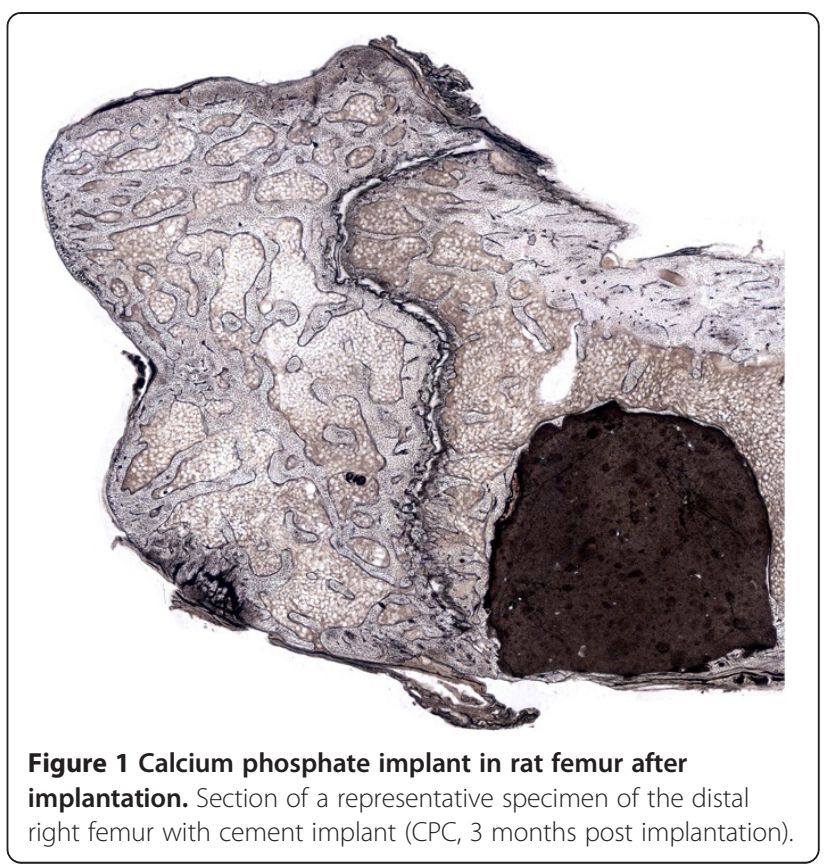

\section{Cement}

\section{Calcium phosphate cement}

The solid phase of CPC consisted of $61 \%$ tricalcium phosphate (TCP), 26\% calcium hydrogen phosphate $\left(\mathrm{CaHPO}_{4}\right.$, anhydrous), $10 \%$ calcium carbonate $\left(\mathrm{CaCO}_{3}\right)$, and $3 \%$ precipitated hydroxyapatite (pHA). The liquid phase of CPC was an aqueous solution of $2 \%$ disodium hydrogen phosphate $\left(\mathrm{Na}_{2} \mathrm{HPO}_{4}\right)$. The compression strength of $\mathrm{CPC}$ was $60 \mathrm{MPa}$ (24 h after preparation).

\section{Strontium-containing calcium phosphate cement}

The solid phase of SPC consisted of $65.2 \%$ tricalcium phosphate (TCP), 21.8\% strontium hydrogen phosphate $\left(\mathrm{SrHPO}_{4}\right.$, anhydrous), $10.8 \%$ strontium carbonate $\left(\mathrm{SPCO}_{3}\right)$, and $2.2 \%$ precipitated hydroxyapatite (pHA). The liquid phase of SPC was an aqueous solution of $3 \mathrm{M}$ dipotassium hydrogen phosphate $\left(\mathrm{K}_{2} \mathrm{HPO}_{4}\right)$ and $1.5 \mathrm{M}$ potassium dihydrogen phosphate $\left(\mathrm{KH}_{2} \mathrm{PO}_{4}\right)$, with a volume ratio of 1:1. The compression strength of SPC was $34 \mathrm{MPa}(24 \mathrm{~h}$ after preparation).

\section{Histomorphometric evaluation}

After embedding the specimen in polymethylmethacrylate (PMMA), the slices for histological evaluation were gained by slicing the PMMA blocks containing undecalcified bone specimen with a diamond band saw (Exakt GmbH, Norderstedt, Germany) and subsequent grinding of the slices to a thickness of $100 \mu \mathrm{m}$. The thin ground sections were mounted on plastic slides and photographed digitally with 25-fold magnification. Measurements were performed with AxioVision software (Carl Zeiss Vision GmbH, 
Oberkochen, Germany). The following histomorphometric parameters were determined:

\section{Circumferential contact index}

Implant circumference (c in Figure 2) and the length of all circumferential segments with direct contact between implant and bone (b in Figure 2) were measured. Circumferential contact index was defined as $(b / c \times 100(\%))$. This parameter was determined at 1,3 , and 6 months after implantation. Contact segments of newly formed bone within the implant were ignored in order to keep this parameter independent from the other parameters mentioned below (Figure 2).

\section{Ingrowth index}

Cement implant area (A in Figure 3) and the area of newly formed bone within the implant (I in Figure 3) were measured. Ingrowth index was defined as $(I / A \times 100(\%))$. This parameter was determined at 1,3 , and 6 months after implantation (Figure 3).

\section{Implant discontinuities}

The total number of discontinuities within the implant and the number of discontinuities containing newly formed bone were counted at 1,3 , and 6 months after implantation. Only discontinuities with a length greater than half of the implant diameter were considered (Figure 4).

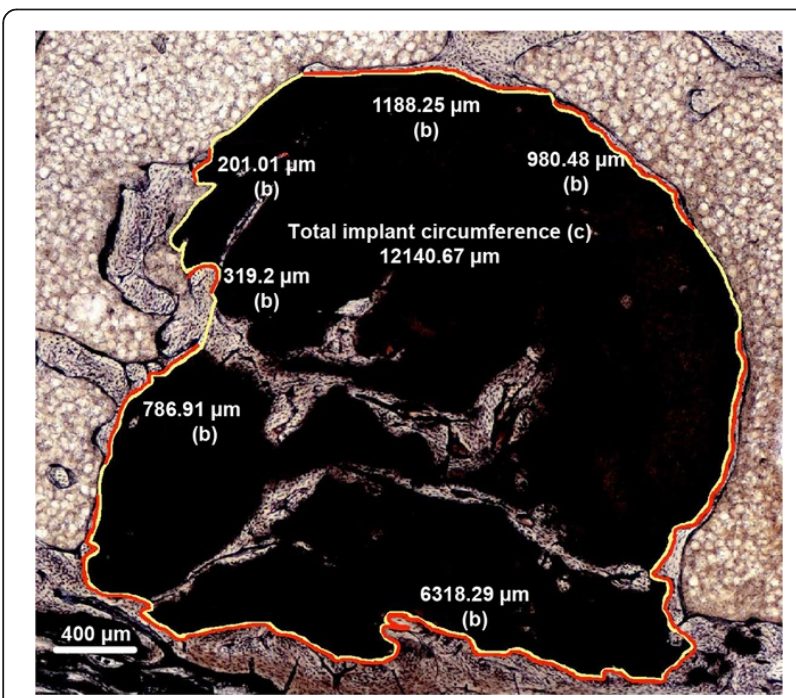

Figure 2 Circumferential contact index. Example of SPC, 6 months after implantation): On the outer surface of the implant, the length of all circumferential segments with direct contact between cement and bone ( $b=$ sum of all red lines) as well as the total implant circumference (c) were measured. Circumferential contact index was defined as $(b / c \times 100(\%))$.

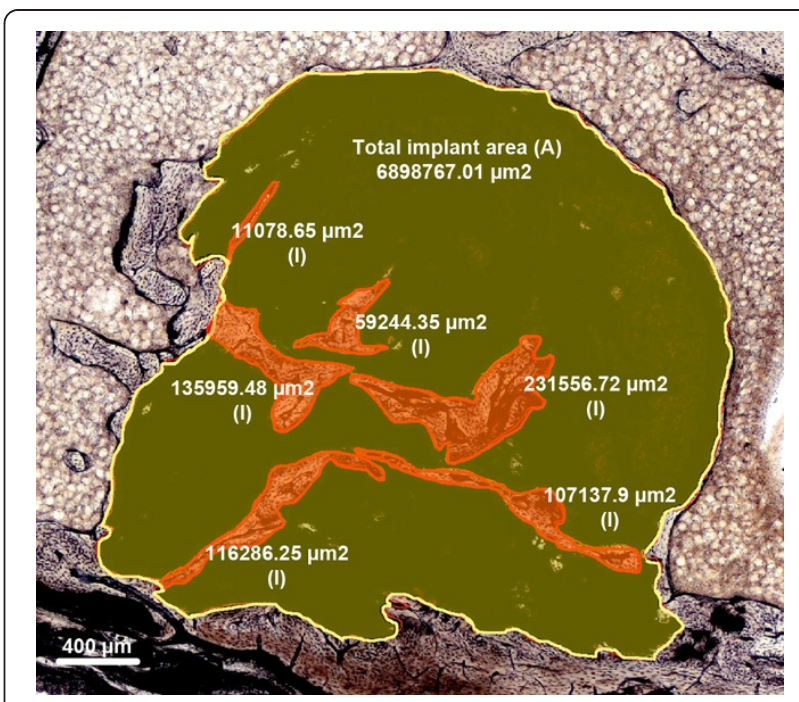

Figure $\mathbf{3}$ Ingrowth index. The relative area of newly formed bone within the implant was measured (SPC, 6 months after implantation). Ingrowth index was defined as (I / A × 100 (\%)).

\section{Evaluation of systemic effects}

\section{Bone mineral density measurement}

In order to evaluate whether locally applied SPC or CPC in the right femur differ in their potential systemic effects on bone mineral density (BMD), BMD was measured with dual X-ray absorptiometry (Piximus device by GE) in the distal metaphysis of the left femur and in the cancellous bone of the second coccygeal vertebra.

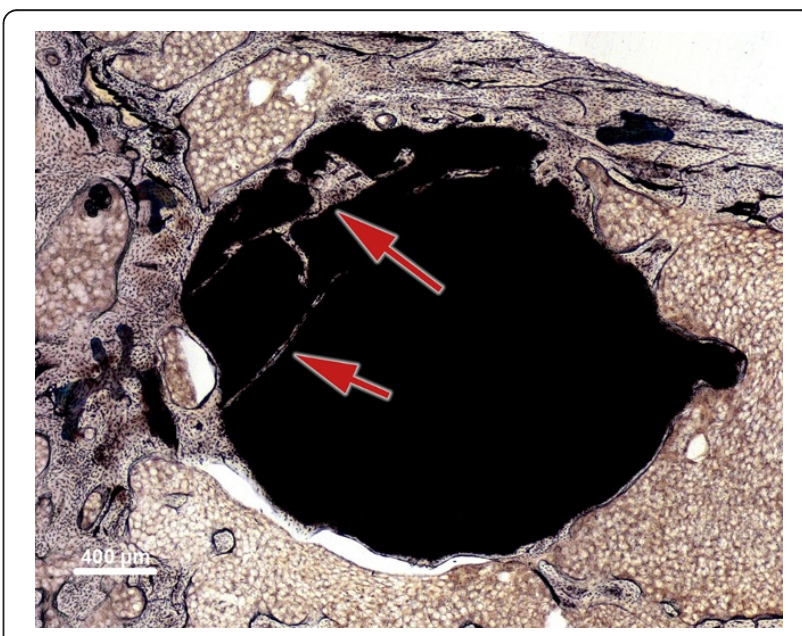

Figure 4 Number of discontinuities. The total number of discontinuities was counted: This specimen has two implant discontinuities (red arrows) containing newly formed bone (SPC, 6 months after implantation) 


\section{Serum strontium levels}

Blood samples of all animals with SPC implants were taken directly after killing. Serum levels of strontium were measured by mass spectrometry.

\section{Statistical analysis}

The Mann-Whitney $U$ test (two-sided, with significance level of $p<0.05$ ) was applied to compare CPC and SPC groups at equal time points $(1,3$, and 6 months after implantation). An overview of sample sizes is given in Table 1.

\section{Results}

\section{Histomorphometric parameters}

\section{Circumferential contact index}

One month after implantation, the circumferential contact index did not differ significantly between the CPC and SPC groups. At 3 and 6 months, circumferential contact index was higher in the SPC group as compared to the CPC group; however, after 6 months this difference was not significant anymore. In both groups, SPC and $\mathrm{CPC}$, the circumferential contact index increased over time (Figure 5).

\section{Ingrowth index}

One month and three months after implantation, the ingrowth index did not differ significantly between the CPC and SPC groups. At 6 months, both groups differed in a highly significant way: While ingrowth index in the CPC group was only $0.33 \%$, it was $3.79 \%$ in the SPC group $(p=0.0002)$ (Figure 6$)$, indicating that after 6 months, a higher percentage of more than ten times in intra-implant bone formation occurred within the SPC implants.

\section{Implant discontinuities}

There were significantly more discontinuities in SPC implants as compared to CPC implants. This was statistically significant at 3 and 6 months after implantation (Figure 7).

Table 1 Sample sizes for statistical analyses

\begin{tabular}{lcccccc}
\hline & \multicolumn{2}{c}{ Histological measurement } & & \multicolumn{2}{c}{ BMD measurement } \\
\cline { 2 - 3 } & CPC $(\boldsymbol{n})$ & SPC $(\boldsymbol{n})$ & & CPC $(\boldsymbol{n})$ & SPC $(\boldsymbol{n})$ \\
\hline 1 month & 8 & 9 & & 10 & 9 \\
\hline 3 months & 8 & 10 & & 9 & 10 \\
\hline 6 months & 9 & 7 & & 9 & 9
\end{tabular}

Of the 60 animals distributed into six groups of ten animals each (CPC and SPC at 1, 3, and 6 months), some got lost for $B M D$ and/or histological measurement. In the 1-month group, two CPC implants disintegrated during preparation, and one animal with SPC had died earlier for unknown reasons. In the 3-month group, one CPC implant disintegrated during preparation, and one animal with $C P C$ had died earlier for unknown reasons. In the 6-month group, two SPC implants disintegrated during preparation, and one animal with $C P C$ and one with SPC had died earlier for unknown reasons.

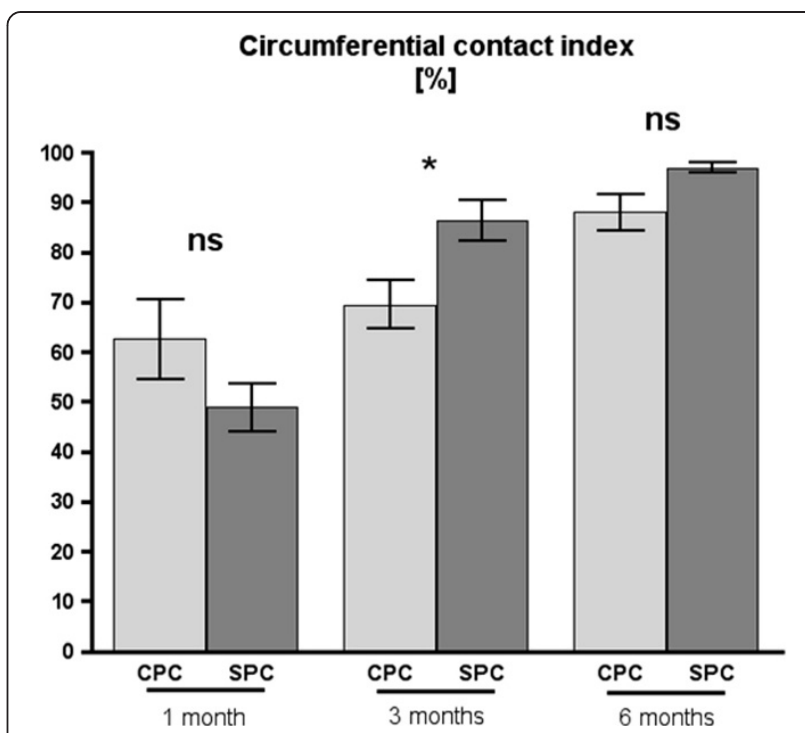

Figure 5 Circumferential contact index. Circumferential contact index for calcium phosphate cement (CPC) and strontium-containing calcium phosphate cement (SPC) at 1, 3, and 6 months after implantation. Three months after implantation, the circumferential contact index is significantly higher for SPC as compared to CPC ( $p=0.009$, as indicated by double asterisk) (mean values \pm standard error, using two-sided Mann-Whitney $U$ test for comparison between CPC and SPC at equal points in time with significance level at $p<0.05)$.

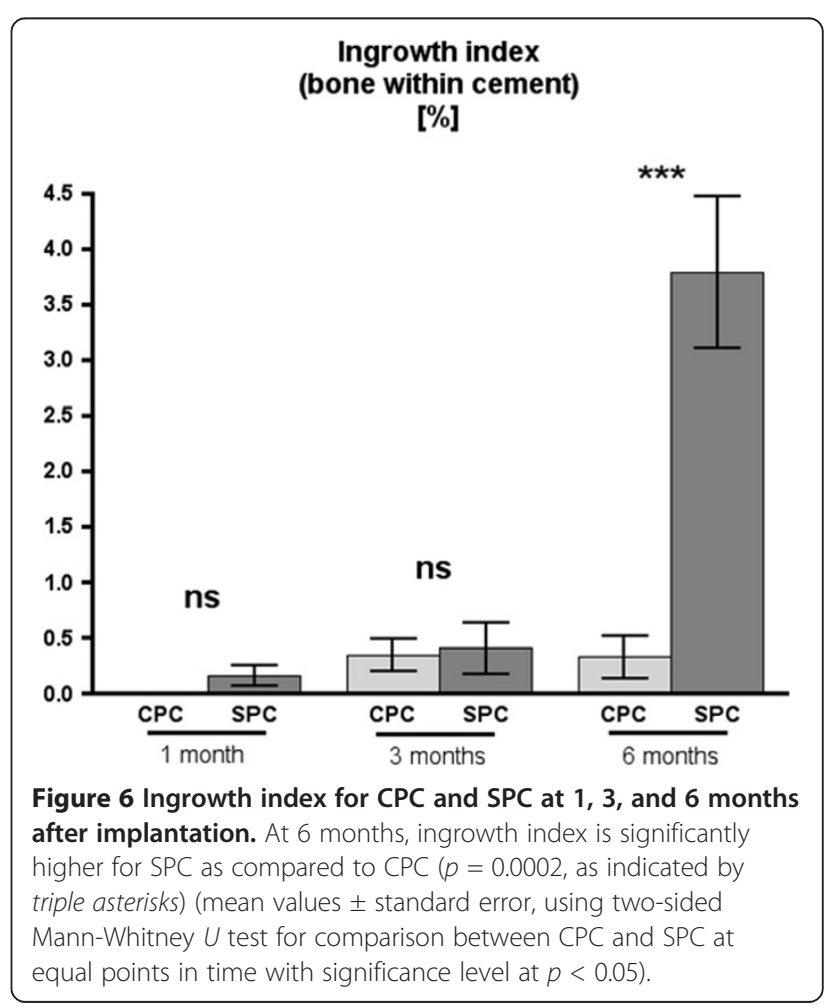




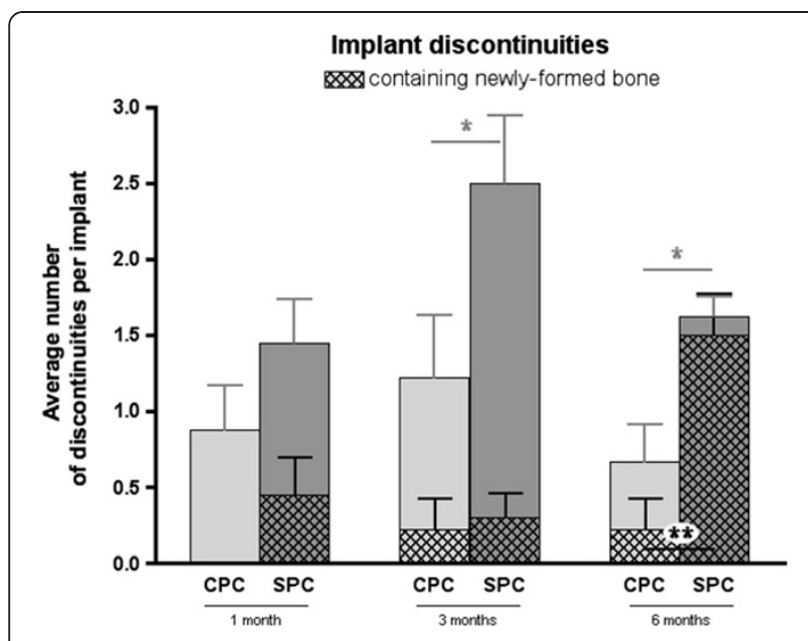

Figure $\mathbf{7}$ Implant discontinuities. Number of implant discontinuities and number of implant discontinuities containing newly formed bone at 1, 3, and 6 months post-implantation. Three months and six months post-implantation, SPC has significantly more discontinuities than CPC. Six months post-implantation, the number of discontinuities containing the newly formed bone is significantly higher in SPC as compared to CPC (mean values \pm standard error, using two-sided Mann-Whitney $U$ test for comparison between CPC and SPC at equal points in time with significance level at $p<0.05$ ).

In both types of cement, the presence of newly-formed bone within these discontinuities increased over time. This effect was much more pronounced in SPC than in CPC implants. Six months after implantation, SPC implants had a significantly higher number of bone-containing discontinuities (on average of 1.5 in SPC and 0.2 in CPC; $p=0.0079$, indicated by double asterisks) (Figure 7).

\section{Systemic parameters}

\section{Bone mineral density}

BMD results are shown in Table 2. No significant difference was found between CPC and SPC groups. However, in the SPC group, there was a consistent increase of bone mineral density in the distal metaphyses of the left (contralateral to the femoral implant site) femora during the observation period.

Table 2 Bone mineral density during 6 months of observation

\begin{tabular}{lccccc}
\hline & \multicolumn{2}{c}{ Coccygeal vertebrae } & & \multicolumn{2}{c}{ Left femora } \\
\cline { 2 - 3 } \cline { 6 - 6 } \cline { 5 - 6 } & CPC & SPC & & CPC & SPC \\
\hline 1 month & $0.261 \pm 0.020$ & $0.274 \pm 0.025$ & & $0.257 \pm 0.015$ & $0.254 \pm 0.038$ \\
\hline 3 months & $0.261 \pm 0.021$ & $0.256 \pm 0.031$ & & $0.262 \pm 0.016$ & $0.267 \pm 0.018$ \\
\hline 6 months & $0.264 \pm 0.012$ & $0.266 \pm 0.026$ & & $0.256 \pm 0.019$ & $0.275 \pm 0.026$ \\
\hline
\end{tabular}

Bone mineral density $\left(\mathrm{g} / \mathrm{cm}^{2}\right)$ of the second coccygeal vertebrae and at the distal metaphyses of the left femora 1, 3, and 6 months after implantation (arithmetic mean \pm standard deviation).

\section{Serum strontium levels}

Serum strontium concentrations (mean \pm standard deviation) in the SPC group at 1, 3, and 6 months were $10.87 \pm 4.16 \mu \mathrm{g} / \mathrm{l}, 3.73 \pm 0.88 \mu \mathrm{g} / \mathrm{l}$, and $1.80 \pm 0.39 \mu \mathrm{g} / \mathrm{l}$, respectively.

\section{Discussion}

\section{Local effects of strontium-containing cement}

This work demonstrates that the addition of strontium to calcium phosphate cement enhances local bone formation in ovariectomized rats, both on the implant surface and within the implant. In vitro experiments provide possible explanations for the observed bone formation stimulating effect of locally applied strontium. Divalent strontium ions enhance the replication of pre-osteoblastic cells and bone matrix synthesis by binding to the calcium receptor and stimulation of local growth factor and osteoprotegerin production [13,22,23].

The histomorphometric evaluation of the implants suggests that the degradation process of calcium phosphate implants is based on the formation of discontinuities within the implant, which are subsequently filled with newly formed bone. While the number of discontinuities in calcium phosphate implants remained constant over the observation period, the number of discontinuities gradually increased in strontium-containing implants. Bone formation within implant discontinuities was strongly influenced by the presence of strontium. More than nine out of ten discontinuities in strontium cement implants contained newly formed bone after 6 months, compared to only four out of ten discontinuities in calcium phosphate cement implants.

The physicochemical properties of the strontiumcontaining implant determine its osteotropic effects and its mechanical properties. The solubility of calcium phosphates in which part of the $\mathrm{Ca}^{2+}$ ions are replaced by $\mathrm{Sr}^{2+}$ ions increases with increasing content of strontium ions due to the larger atomic radius of $\mathrm{Sr}^{2+}$ which reduces crystallinity and alters the crystal lattice [24-27]. The higher solubility of the SPC compared to the CPC could also explain the higher degree of discontinuities within the SPC group, which may compromise the biomechanical stability of the implant.

Different types of strontium-containing cements have been tested in vivo previously: In rabbit non-osteoporotic cancellous bone, an injectable strontium-containing cement with an acrylate component was compared to PMMA cement [28]. The stimulation of bone formation at the bone-implant interface was found on strontiumcontaining cement surfaces only, whereas inflammatory responses, necrosis, and a fibrous layer were found at the PMMA-cement-bone interface [28]. Another calcium phosphate cement containing strontium and acrylate was developed by $\mathrm{Lu}$, Cheung, and co-workers, which also 
exhibited direct contact between bone and strontiumcontaining cement [29,30]. Guo Dagang and co-workers [31,32] demonstrated biocompatibility and degradability of their strontium-containing hydroxyapatite in rabbit muscle and cancellous bone.

The addition of strontium to different types of cement also affects the compression strength of the material in different ways. Panzavolta et al. [23] describe a strontiumenriched gelatin-calcium phosphate cement: Its compressive strength decreases with increasing strontium content ( $0.1 \%$ to $5 \%)$. However, Wang et al. [33], who added strontium carbonate as a radio-opacifier to calcium phosphate cement, observed an increase in compressive strength from 0 wt.\% to 8 wt.\% strontium carbonate but with a subsequent decrease in compressive strength when increasing the strontium carbonate content to $20 \mathrm{wt} . \%$. The absolute figure for compression strength for cement with 20 wt.\% strontium [31-33] was similar to the one in our study (36 MPa as compared to SPC used in our study with $34 \mathrm{MPa}$ ). It is unclear how mechanical cement properties affect the degradation processes in bone tissue. Cements implanted into a cavity surrounded by femoral bone - as performed in our study - are somewhat shielded from mechanical loading. Despite this shielding, compressive forces and shear stress within the implant are possibly due to the elastic deformation of the surrounding bone when the animal puts weight on the femur when moving. It is therefore likely that formation of discontinuities and eventually cement degradation is influenced by the mechanical properties of the cement, which may also have clinical implications when calcium phosphate cements are implanted in bone sites exposed to shear stress rather than compressive force.

Unlike the local positive effects of strontium-containing cements on osseointegration, we did not find a significant systemic effect on bone density of strontium-containing cement implants. BMD in the examined vertebrae did not differ between animals with calcium phosphate and strontium-containing calcium phosphate implants in the right femur. In the contralateral femur, bone mineral density increased by approximately $8 \%$ in animals with strontium-containing cement from 1 to 6 months after implantation. No such increase was observed in the calcium phosphate group; however, the difference in BMD values between the SPC and CPC groups was not significant at any point in time. When considering these observations, we have to keep in mind a peculiarity of the used rat animal model. The ovariectomized rats' skeleton is still growing during the observation period, and the growth rate at the epiphyseal plates is usually high in ovariectomized rats [34]. If the serum levels of strontium are elevated shortly after implantation, part of the serum strontium is likely to be deposited in the growing bone. The more bone tissue is growing, the more strontium can be deposited into the newly formed bone matrix, and in fact higher concentrations of strontium were observed in newly formed bone than in old bone in other studies $[35,36]$. BMD measurements in strontium-containing bone are falsely high, due to the higher atomic number $(Z=38)$ of strontium as compared to calcium $(Z=20)$ $[25,37,38]$. The increase in femoral BMD over time while vertebral $B M D$ remains unchanged may therefore be due to the differences in relative growth between the femur and spine during the observation period.

Another possible reason for increased contralateral femoral BMD while spinal BMD remains unaffected could be the different loading conditions of the respective skeletal sites. In the rat, mechanical load on the coccygeal vertebrae is lower compared to the load on a weight-bearing femur. A study which investigated an effect of different loading conditions on BMD under systemic application of strontium was performed by Hott et al. [39]: Bone resorption induced by immobilization in rats can be suppressed by systemic administration of strontium. Whether bone formation under application of strontium is possibly enhanced by mechanical loading or not has not been shown.

Oral administration of strontium ranelate increases bone mineral density in ovariectomized rats' femur, even after correction for higher X-ray absorption [15]. The lowest strontium ranelate dose in a rat experiment of $77 \mathrm{mg} / \mathrm{kg} /$ day orally led to a serum strontium concentration of $24.2 \mu \mathrm{g} / \mathrm{l}$ [15], which is more than twice the concentration we measured in the serum 1 month after implantation of the strontium-containing cement. The oral dose that raised BMD most in the study by Marie et al. [15] (308 mg/kg/day) led to a serum strontium concentration of $127.6 \mu \mathrm{g} / \mathrm{l}$, which is an order of magnitude higher than our highest serum concentration. In another study, Marie et al. demonstrated a substantial improvement of mechanical properties of the fifth lumbar vertebra in ovariectomized rats treated with oral strontium ranelate $(625 \mathrm{mg} / \mathrm{kg} /$ day $)$ [40]. Ultimate strength was increased by $26 \%$ and energy to failure by $75 \%$. To achieve this mechanical improvement, the maximum oral strontium dose of their previous study [15] was more than doubled. The serum strontium concentration necessary to produce systemic effects was approximately 100 times higher than the one measured in our study [41].

There are several shortcomings of our study. The mechanical properties of the utilized cements in this study were tested under in vitro conditions by the manufacturer. Thus, it is unclear whether the indicated compressive strengths of the two cement types in our study remain constant after in vivo implantation. Confounding factors are the presence of body fluids and possible mechanical stress by inserting instruments during the crystallization phase; the surgical application procedure may at least in 
part be responsible for implant discontinuities and thus play a role in the subsequent degradation processes, thereby influencing resorption and eventually replacement of the implant.

The cements used in our study are resorbable; however, due to the lack of a long-term follow-up, we do not know whether the used cements are indeed replaceable by bone tissue and to what extent.

The parameters 'ingrowth index' and 'implant discontinuities containing bone' are not independent of each other and thus describe the osseointegration characteristics of the used cements with different parameters. After 6 months, a large proportion of the bone tissue quantified by the ingrowth index was actually located within linear implant discontinuities. New bone formation on the circumference of the original implant ('circumferential contact index'), however, has been quantified as a parameter which is independent from the ingrowth indices (ingrowth index and implant discontinuities containing bone).

When assessing the bone mineral density after application of the implant containing strontium, we did not correct the higher X-ray absorption of strontium. Our BMD measurement may therefore produce falsely high values. This must be taken into account in case our absolute values are to be compared with others. The interpretation of our results, however, remains unchanged even if we corrected for bone strontium content, as we did not detect any significant systemic effects of locally applied strontium-containing implants on BMD at other skeletal sites.

\section{Conclusions}

The addition of strontium to calcium-phosphate cement leads to a faster osseointegration of the implant into the osteoporotic bone. Strontium-containing implants stimulate, at least initially, local bone formation and are partly replaced by bone within 6 months.

Serum concentrations of strontium caused by release from the strontium-containing implants in this model are too low to stimulate systemic bone formation and thus do not increase bone mineral density systemically.

The clinical relevance of the observation of an initially faster osseointegration of strontium-containing implants and its biomechanical implications still have to be demonstrated by a long-term, randomized, controlled clinical trial.

\section{Competing interests}

RW is an employee of Medtronic $\mathrm{GmbH}$. All other authors have no competing interest.

\section{Authors' contributions}

MB carried out data evaluation and editing of the manuscript. PS, US, WR, and IG performed the animal experiments. RK is responsible for the editorial work. PJM and PPN are both involved in the supervision of this work. CK designed the project, performed the experiments and edited the manuscript. All authors read and approved the final manuscript.

\section{Acknowledgments}

This study was supported by the Medtronic GmbH (Meerbusch, Germany) and the Havemann family. Medtronic supplied the employed cement material; the Havemann family sponsored the salary for US, MSc. The Hopp foundation (Sankt Leon-Rot, Germany) sponsored the supplies for the histomorphometric evaluation.

\section{Author details}

'Division of Traumatology, University of Heidelberg, Schlierbacher Landstraße 200a, Heidelberg 69118, Germany. ${ }^{2}$ Division of Osteology, Department of Medicine I and Clinical Chemistry, University of Heidelberg, Im Neuenheimer Feld 410, 69120, Heidelberg, Germany. ${ }^{3}$ Medtronic GmbH, Earl-Bakken-Platz 1, Meerbusch 40670, Germany.

Received: 3 February 2013 Accepted: 21 May 2013

Published: 7 June 2013

\section{References}

1. Albee FH: Studies in bone growth: triple calcium phosphate as a stimulus to osteogenesis. Ann Surg 1920, 71:32-39.

2. Ray RD, Ward AA Jr: A preliminary report on studies of basic calcium phosphate in bone replacement. Surg Forum 1951, 1951:429-434.

3. Brown WE, Chow OLC: Dental restorative cement pastes. 1995. US Patent no. 4518430.

4. Illi OE, Feldmann CP: Stimulation of fracture healing by local application of humoral factors integrated in biodegradable implants. Eur J Pediatr Surg 1998, 8:251-255.

5. Friess W, Uludag H, Foskett S, Biron R, Sargeant C: Characterization of absorbable collagen sponges as rhBMP-2 carriers. Int J Pharm 1999, 187:91-99.

6. Woo BH, Fink BF, Page R, Schrier JA, Jo YW, Jiang G, DeLuca M, Vasconez HC, Deluca PP: Enhancement of bone growth by sustained delivery of recombinant human bone morphogenetic protein-2 in a polymeric matrix. Pharm Res 2001, 18:1747-1753.

7. Yokota S, Uchida T, Kokubo S, Aoyama K, Fukushima S, Nozaki K, Takahashi T, Fujimoto R, Sonohara R, Yoshida M, Higuchi S, Yokohama S, Sonobe T: Release of recombinant human bone morphogenetic protein 2 from a newly developed carrier. Int J Pharm 2003, 251:57-66.

8. Cook SD, Dalton JE, Tan EH, Whitecloud TS, Rueger DC: In vivo evaluation of recombinant human osteogenic protein (rhOP-1) implants as a bone graft substitute for spinal fusions. Spine (Phila Pa 1976) 1994, 1655:1663-1655.

9. Min SX, Jin AM, Tong BH, Zhu LX, Tian J: Three-dimensional porous polyDL-lactide/basic fibroblast growth factor composites for bone defect repair: an experimental study. Di Yi Jun Yi Da Xue Xue Bao 2003, 23:318-322.

10. Arm DM, Tencer AF, Bain SD, Celino D: Effect of controlled release of platelet-derived growth factor from a porous hydroxyapatite implant on bone ingrowth. Biomaterials 1996, 17:703-709.

11. Laffargue $P$, Fialdes $P$, Frayssinet $P$, Rtaimate $M$, Hildebrand HF, Marchandise $X$ : Adsorption and release of insulin-like growth factor-I on porous tricalcium phosphate implant. J Biomed Mater Res 2000, 49:415-421.

12. Marie PJ, Garba MT, Hott M, Miravet L: Effect of low doses of stable strontium on bone metabolism in rats. Miner Electrolyte Metab 1985, 11:5-13.

13. Canalis $E$, Hott M, Deloffre $P$, Tsouderos $Y$, Marie PJ: The divalent strontium salt S12911 enhances bone cell replication and bone formation in vitro. Bone 1996, 18:517-523.

14. Verberckmoes SC, De Broe ME, D'Haese PC: Dose-dependent effects of strontium on osteoblast function and mineralization. Kidney Int 2003, 64:534-543.

15. Marie PJ, Hott M, Modrowski D, De Pollak C, Guillemain J, Deloffre P, Tsouderos $Y$ : An uncoupling agent containing strontium prevents bone loss by depressing bone resorption and maintaining bone formation in estrogen-deficient rats. J Bone Miner Res 1993, 8:607-615.

16. Buehler J, Chappuis P, Saffar JL, Tsouderos Y, Vignery A: Strontium ranelate inhibits bone resorption while maintaining bone formation in alveolar bone in monkeys (Macaca fascicularis). Bone 2001, 29:176-179.

17. Marie PJ, Ammann P, Boivin G, Rey C: Mechanisms of action and therapeutic potential of strontium in bone. Calcif Tissue Int 2001, 69:121-129.

18. Reginster JY, Seeman E, De Vernejoul MC, Adami S, Compston J, Phenekos C, Devogelaer JP, Curiel MD, Sawicki A, Goemaere S, Sorensen $\mathrm{OH}$, Felsenberg D, Meunier PJ: Strontium ranelate reduces the risk of nonvertebral fractures in postmenopausal women with osteoporosis: 
treatment of peripheral osteoporosis (TROPOS) study. J Clin Endocrinol Metabol 2005, 90:2816-2822.

19. Meunier PJ, Roux C, Seeman E, Ortolani S, Badurski JE, Spector TD, Cannata J, Balogh A, Lemmel EM, Pors-Nielsen S, Rizzoli R, Genant HK, Reginster JY: The effects of strontium ranelate on the risk of vertebral fracture in women with postmenopausal osteoporosis. N Engl J Med 2004, 350:459-468.

20. Turner RT, Maran A, Lotinun S, Hefferan T, Evans GL, Zhang M, Sibonga JD: Animal models for osteoporosis. Rev Endocr Metab Disord 2001, 2:117-127.

21. Jee WS, Yao W: Overview: animal models of osteopenia and osteoporosis. J Musculoskelet Neuronal Interact 2001, 1:193-207.

22. Peng S, Liu XS, Wang T, Li Z, Zhou G, Luk KD, Guo XE, Lu WW: In vivo anabolic effect of strontium on trabecular bone was associated with increased osteoblastogenesis of bone marrow stromal cells. J Orthop Res 2010, 28:1208-1214.

23. Panzavolta S, Torricelli P, Sturba L, Bracci B, Giardino R, Bigi A: Setting properties and in vitro bioactivity of strontium-enriched gelatin-calcium phosphate bone cements. J Biomed Mater Res 2008, 84:965-972.

24. Okayama S, Akao M, Nakamura S, Shin Y, Higashikata M, Aoki H: The mechanical properties and solubility of strontium-substituted hydroxyapatite. Bio-Med Mater Eng 1991, 1:11-17.

25. Christoffersen J, Christoffersen MR, Kolthoff N, Barenholdt O: Effects of strontium ions on growth and dissolution of hydroxyapatite and on bone mineral detection. Bone 1997, 20:47-54

26. Verberckmoes SC, Behets GJ, Oste L, Bervoets AR, Lamberts LV, Drakopoulos M, Somogyi A, Cool P, Dorrine W, De Broe ME, D'Haese PC: Effects of strontium on the physicochemical characteristics of hydroxyapatite. Calcif Tissue Int 2004, 75:405-415.

27. Ni GX, Lu WW, Xu B, Chiu KY, Yang C, Li ZY, Lam WM, Luk KD: Interfacial behaviour of strontium-containing hydroxyapatite cement with cancellous and cortical bone. Biomaterials 2006, 27:5127-5133.

28. Wong CT, Lu WW, Chan WK, Cheung KM, Luk KD, Lu DS, Rabie AB, Deng LF, Leong JC: In vivo cancellous bone remodeling on a strontium-containing hydroxyapatite (Sr-HA) bioactive cement. J Biomed Mater Res 2004, 68:513-521.

29. Lu WW, Cheung KM, Li YW, Luk KD, Holmes AD, Zhu QA, Leong JC: Bioactive bone cement as a principal fixture for spinal burst fracture: an in vitro biomechanical and morphologic study. Spine 2001, 26:2684-2690. discussion 2690-2681.

30. Cheung KM, Lu WW, Luk KD, Wong CT, Chan D, Shen JX, Qiu GX, Zheng ZM, Li CH, Liu SL, Chan WK, Leong JC: Vertebroplasty by use of a strontium-containing bioactive bone cement. Spine 2005, 30:584-S91.

31. Guo D, Xu K, Zhao X, Han Y: Development of a strontium-containing hydroxyapatite bone cement. Biomaterials 2005, 26:4073-4083.

32. Dagang $\mathrm{G}$, Kewei $\mathrm{X}$, Yong $\mathrm{H}$ : The influence of $\mathrm{Sr}$ doses on the in vitro biocompatibility and in vivo degradability of single-phase $\mathrm{Sr}$ incorporated HAP cement. J Biomed Mater Res 2008, 86:947-958.

33. Wang $X$, Ye J, Wang $Y$ : Influence of a novel radiopacifier on the properties of an injectable calcium phosphate cement. Acta Biomater 2007, 3:757-763.

34. Wronski TJ, Lowry PL, Walsh CC, Ignaszewski LA: Skeletal alterations in ovariectomized rats. Calcif Tissue Int 1985, 37:324-328.

35. Boivin G, Deloffre P, Perrat B, Panczer G, Boudeulle M, Mauras Y, Allain P, Tsouderos Y, Meunier PJ: Strontium distribution and interactions with bone mineral in monkey iliac bone after strontium salt (S 12911) administration. J Bone Miner Res 1996, 11:1302-1311.

36. Roschger P, Manjubala I, Zoeger N, Meirer F, Simon R, Li C, Fratzl-Zelman N, Misof BM, Paschalis EP, Streli C, Fratzl P, Klaushofer K: Bone material quality in transiliac bone biopsies of postmenopausal osteoporotic women after 3 years of strontium ranelate treatment. J Bone Miner Res 2010, 25:891-900.

37. Blake GM, Fogelman I: Long-term effect of strontium ranelate treatment on BMD. J Bone Miner Res 2005, 20:1901-1904.

38. Blake GM, Fogelman I: Theoretical model for the interpretation of BMD scans in patients stopping strontium ranelate treatment. J Bone Miner Res 2006, 21:1417-1424.

39. Hott M, Deloffre P, Tsouderos Y, Marie PJ: S12911-2 reduces bone loss induced by short-term immobilization in rats. Bone 2003, 33:115-123.
40. Marie PJ, Ammann P, Shen V, Bain SD, Robin B, Dupin-Roger I: Evidence that strontium ranelate increases bone quality in rats by improving bone strength and architecture. Bone 2003, 32(5):S80. OR29W.

41. Fuchs RK, Allen MR, Condon KW, Reinwald S, Miller LM, McClenathan D, Keck B, Phipps RJ, Burr DB: Strontium ranelate does not stimulate bone formation in ovariectomized rats. Osteoporos Int 2008, 19:1331-1341.

doi:10.1186/1749-799X-8-16

Cite this article as: Baier et al: Strontium enhances osseointegration of calcium phosphate cement: a histomorphometric pilot study in ovariectomized rats. Journal of Orthopaedic Surgery and Research 2013 8:16.

\section{Submit your next manuscript to BioMed Central and take full advantage of:}

- Convenient online submission

- Thorough peer review

- No space constraints or color figure charges

- Immediate publication on acceptance

- Inclusion in PubMed, CAS, Scopus and Google Scholar

- Research which is freely available for redistribution 